\title{
ARTIKELEN
}

\section{Spreken is zilver, zwijgen is fout}

\section{Over het wetsvoorstel Zwijgcontracten in de zorg}

\author{
Mr. dr. Ph.S. Kahn*
}

\section{Inleiding}

Dit voorjaar is het wetsvoorstel over zwijgcontracten in de gezondheidszorg via internet in consultatie $^{1}$ gegaan. Hiermee is een langdurige discussie in de Tweede Kamer beslecht over de vraag of het verbieden van zwijgclausules in contracten over incidenten in de zorgverlening nu wel of niet een specifieke wettelijke regeling behoeft. Het gaat hier om zwijgbedingen in de zorg in de breedte. ${ }^{2}$ Dergelijke bedingen kunnen betrekking hebben op het überhaupt zwijgen over een ernstig incident dat de patiënt is overkomen, het afzien van een gang naar de tuchtrechter, het doen van aangifte bij politie of justitie, of het zwijgen over het incident naar de Inspectie Gezondheidszorg en Jeugd (IGJ). ${ }^{3}$ Er bestaat brede consensus over de onwenselijkheid van dergelijke bedingen. Er zijn nu al juridische handvatten om hier tegen op te treden, zowel voor de patiënt als voor de IGJ. De bedoeling van het wetsvoorstel is duidelijk te maken dat dergelijke bedingen in (vaststellings)overeenkomsten onacceptabel en vanaf het moment van totstandkoming nietig zijn. Dit in aansluiting op de algemene bepalingen uit het Burgerlijk Wetboek ${ }^{4}$ en wet- en regelgeving in de zorg. Belangrijker misschien nog wel is het politieke signaal dat de minister hiermee wil afgeven.

\section{Aanleiding}

Er heeft zich een aantal gevallen in de zorg voorgedaan over (vermeende) zwijgcontracten in vaststellingsovereenkomsten, die in de discussie in de Kamer hebben geleid tot dit wetsvoorstel. Een zaak die - los van het (door de media getypeerde) zwijgcontract - veel persaandacht heeft gekregen is de casus, november 2014, van de Gooise hockeyer die onverwacht kwam te overlijden. De zaak gaf aanleiding tot Kamervragen, onder meer over het instellen van een wettelijk verbod op zwijgcontracten. ${ }^{5}$ Het leidde tevens tot een door de

* Philip Kahn is secretaris raad van bestuur van Franciscus Gasthuis \& Vlietland te Rotterdam/Schiedam.

1 www.internetconsultatie.nl/zwijgcontracten. De internetconsultatie startte op 11 maart 2020 en duurde tot 1 juni 2020. De reacties passeren later in dit artikel de revue.

2 De reguliere zorg (Wkkgz, Wet kwaliteit, klachten en geschillen zorg), de jeugdzorg (Jeugdwet) en de ondersteuning (Wmo, Wet maatschappelijke ondersteuning).

3 J. Legemaate, 'Zwijgcontracten in de zorg', Ars Aequi oktober 2016, p. 702-704.

4 Art. 3:40 lid 1 en 2 BW, art. 6:248 BW en art. 7:902 BW.

5 Eind 2016, begin 2017: Aanhangsel Handelingen II 2016/17, 1103, p. 1 e.v., in het bijzonder p. 5. 
inspectie ingediende tuchtklacht en een strafrechtelijk onderzoek. ${ }^{6}$ Het ziekenhuis stelde een externe onafhankelijke commissie in, hetgeen uitmondde in een zeer gedegen onderzoeksrapport. ${ }^{7}$ De onderzoekscommissie achtte in deze casus ${ }^{8}$ geen zwijgcontract aanwezig omdat de daarvoor in aanmerking komende bepalingen over het intrekken van een aangifte, het niet indienen van tuchtklachten en het onthouden van contacten met de media juist op verzoek van de advocaat van de moeder van de patiënt in het contract waren opgenomen. De commissie oordeelt dat, ook al heeft de advocaat van de nabestaanden deze zwijgclausules voorgesteld, dit onverlet laat dat het opnemen van beperkende bepalingen ongewenst was. ${ }^{9}$

Een andere zaak die de roep om een verbod op zwijgcontracten deed zwellen was de zaak 'Cordaan' waarbij de instelling verstandelijk gehandicapten een zwijgcontract liet tekenen over financiële malversaties bij patiënten en geestelijke en fysieke mishandeling, die jaren voortduurden. ${ }^{10}$ Dit werd in 2014, een jaar nadat de incidenten aan het licht kwamen, door Cordaan bij de IGJ gemeld. In deze zaak bevestigde de minister opnieuw zwijgcontracten te verwerpen, maar gaf nu veel scherper aan hierin aanleiding te zien tot voorbereiding van wetgeving die zwijgcontracten in de zorg moet verbieden. Eerder (in 2001) was sprake van een zwijgcontract tussen een slachtoffer / gedupeerde patiënt van de disfunctionerende neuroloog en de raad van bestuur van het Enschedese Medisch Spectrum Twente. ${ }^{11}$ Ook kan worden gewezen op zwijgcontracten in de jeugdbescherming (Veilig Thuis) en daar gehanteerde zwijgcontracten. ${ }^{12}$

Hoe ernstig deze calamiteiten en de in deze casus opgestelde zwijgcontracten ook zijn geweest, het aantal zwijgcontracten is, althans voor zover daarop zicht bestaat, beperkt. Uit onderzoek van de toenmalige IGZ in 2016-2017 naar het vóórkomen van zwijgcontracten bleek dat er 55 meldingen werden gedaan afkomstig uit de zorg en daarvan bleken er 'maar' acht contractuele afspraken te bevatten die ongewenst zijn. ${ }^{13}$

6 De longarts kreeg een waarschuwing (maart 2017); er werd geen strafrechtelijke vervolging ingesteld (juli 2017).

7 'Een tragische gebeurtenis in Tergooi', rapport onafhankelijke onderzoekscommissie, 19 december 2016.

8 De casus is aanvankelijk door de raad van bestuur niet als calamiteit bij de IGJ gemeld. Toen de moeder van patiënt een klacht indiende bij de klachtencommissie van het ziekenhuis, gebeurde dit wel. De IGJ concludeerde dat wél sprake was van een calamiteit en verrichtte eigen onderzoek. De onafhankelijke onderzoekscommissie meent dat, alles afwegend, er ruim voldoende aanleiding bestond om dit ernstige incident te kwalificeren als calamiteit. Zie 'Een tragische gebeurtenis in Tergooi', p. 29 en 45.

9 'Een tragische gebeurtenis in Tergooi', p. 35-37 en 46.

10 Zomer 2019: Aanhangsel Handelingen II 2018/19, 3916, p. 1 e.v.

11 In het zwijgcontract staat dat het medisch dossier door partijen zou worden vernietigd en patiënte de klacht- en tuchtrechtelijke procedure zou staken, een en ander op straffe van een geldboete. Zie RTV Oost, 10 april 2016.

12 Antwoorden van de ministers voor Rechtsbescherming en VWS van 19 maart 2019, nr. $2019 Z 01632$ en van 2 maart 2020, nr. $2020 \mathrm{Z} 00715$.

13 Vaststellingsovereenkomsten in de zorg, rapport IGZ, mei 2017, p. 7. Ook Kamerstukken II 2016/17, 31016, nr. 98, p. 12 en Kamerstukken II 2017/18, 31016, nr. 108, p. 34. Het betrof de periode april 2016 tot april 2017. 


\section{Het juridisch kader}

De term zwijgcontract is geen juridisch begrip en eigenlijk wordt hiermee gedoeld op een geheimhoudingsbeding in een contract. Als de overeengekomen geheimhouding (uitsluitend) betrekking heeft op de inhoud van de overeenkomst of de afgesproken schadevergoeding, dan is hiermee alleen het belang van partijen gemoeid en is daar niet zoveel mis mee. Anders ligt het bij een zwijgbeding waarbij beoogd wordt een tuchtprocedure te voorkomen of melding van het incident bij de inspectie te blokkeren. Daar raakt het een algemeen, publiek belang dat gebaat is bij openheid en het kunnen toetsen van de kwaliteit van zorg. ${ }^{14}$ De minister spreekt van 'vaststellingsovereenkomsten met ongewenste geheimhoudingsbepalingen, die een belemmering vormen voor openheid en transparantie in de zorg. ${ }^{15}$

Het is goed een onderscheid te maken tussen het civielrechtelijke en het bestuursrechtelijke kader.

In het licht van de discussie over de privaatrechtelijke geoorloofdheid van zwijgcontracten vormt artikel 3:40 BW een kernbepaling. Iets minder pregnant spelen nog de artikelen 7:902 BW en 6:248 BW een rol. In artikel 3:40 BW is in lid 1 bepaald dat een rechtshandeling die door inhoud of strekking strijdig is met de goede zeden of openbare orde, nietig is. Lid 2 van dat artikel geeft aan dat strijd met een dwingende wetsbepaling (eveneens) leidt tot nietigheid, tenzij het een bepaling is die tot rechtsbescherming strekt van een der partijen. In dat geval kan de vernietigbaarheid van het betreffende beding door die partij worden ingeroepen. Artikel 7:902 BW geeft aan dat ook al mocht een (deel van een) vaststellingsovereenkomst in strijd blijken met dwingend recht, zij geldig blijft tenzij zij naar inhoud of strekking in strijd komt met de goede zeden of openbare orde. Dit artikel heeft dus sterke raakvlakken met artikel 3:40 lid 1 BW.

In de zorg bestaat (nog) geen wettelijke bepaling die zwijgcontracten verbiedt, zodat het bepaalde in lid 2 van artikel 3:40 BW hier nu niet aan de orde is. ${ }^{16}$ Hier zal verandering in komen als het wetsvoorstel Zwijgcontracten in de zorg doorgang vindt.

Het bepaalde in artikel 3:40 lid 1 BW - en ook in artikel 7:902 BW - over strijdigheid met de goede zeden geeft wat meer een morele context, waarbij de situatie toen de rechtshandeling werd verricht van belang is. Ook indien slechts één van de prestaties in de overeenkomst in strijd is met de goede zeden (of de openbare orde) is het gestelde in artikel 3:40 lid 1 BW van toepassing. ${ }^{17}$ Strijd met de goede zeden kán worden aangenomen als het beding zodanig in strijd is met het doel of de strekking van een wettelijke regeling dat het daardoor nietig is. ${ }^{18}$ Bij zwijgcontracten in de zorg kan hierbij worden gedacht aan doel en strekking van de Wkkgz inzake openheid en transparantie, inzake de in de Wkkgz 
verplicht gestelde melding bij de IGJ van calamiteiten of geweld in de $\operatorname{zorg}^{19}$ en aan het grondwettelijk verbod met betrekking tot het afhouden van de gang naar de (tucht-, strafof civiele) rechter. ${ }^{20}$ Hierop kom ik hierna terug.

De omstandigheden van de casus zullen bepalend zijn voor de vraag of sprake is van strijd met de goede zeden (art. 3:40 lid 1 of art. 7:902 BW), dan wel of een beroep kan worden gedaan op de aanvullende of juist beperkende werking vanwege de eisen van redelijkheid en billijkheid volgens artikel 6:248 BW. ${ }^{21}$ Bijvoorbeeld in een situatie als die van de Gooise hockeyer, waarbij de betreffende bepalingen op instigatie van de advocaat van de moeder van patiënt in het contract werden opgenomen, zal dit punt zwaar wegen.

Bij gebrek aan een wettelijke bepaling die dergelijke rechtshandelingen verbiedt (vergelijk art. 3:40 lid $2 \mathrm{BW}$ ), kan discussie blijven bestaan en is een gang naar de rechter om vernietiging van het beding af te dwingen onvermijdelijk.

Het bestuursrechtelijk kader in de zorg laat zien dat zwijgcontracten weliswaar niet met zoveel woorden verboden zijn, maar toch in strijd met - tenminste de geest van - wet- en regelgeving kunnen zijn. Gewezen wordt op de Wkkgz waarbij (het bestuur van) de zorgaanbieder ervoor verantwoordelijk is om goede zorg aan te bieden en dat 'de rechten van de cliënt zorgvuldig in acht worden genomen en de cliënt ook overigens met respect wordt behandeld'.22 Ook in artikel 10 lid 3 Wkkgz wordt openheid naar de patiënt of diens nabestaanden voorgeschreven bij incidenten in de zorgverlening. Hierdoor wordt het de patiënt mogelijk gemaakt om op basis van volledige informatie besluiten te nemen van welke aard dan ook, bijvoorbeeld om een klacht- of tuchtprocedure te starten of zich te wenden tot de inspectie. Het strekt hier verder dan alleen het individuele (patiënten)belang, maar raakt ook het grotere belang van de kwaliteit van goede zorg. ${ }^{23}$ Goede zorg impliceert goed bestuur. De Governancecode Zorg (Code) werkte het begrip goed bestuur uit. ${ }^{24}$ De Code staat bol van begrippen over waarden en normen van goed bestuur, waarbij het bestuur verantwoordelijkheid draagt voor een open aanspreekcultuur en een lerende organisatie. Dat zwijgclausules strijdig zijn met hoe een goed bestuurder zich dient te gedragen, lijdt geen twijfel. ${ }^{25}$ Goed bestuur is door de IGJ (toen nog IGZ) en NZa vervolgens uitgewerkt in het toezichtkader 'Toezicht op Goed Bestuur', ${ }^{26}$ waarbij begrippen als open, inte-

19 Engelen plaatst haar vraagtekens bij nietigheid van een zwijgbeding vanwege (uitsluitend) strijdigheid met doel en strekking van de Wkkgz, zie p. 55 van haar artikel en haar conclusie op p. 58. De uitleg en het normstellend kader van de beginselen van openheid en transparantie uit de Wkkgz in de Governancecode Zorg en het toezichtkader IGZ/NZa worden overigens door haar niet genoemd.

20 Het afhouden van de gang naar de rechter is een zwaarwegend argument dat, afhankelijk van de omstandigheden, kan leiden tot vernietiging van het zwijgbeding. Zie Engelen, p. 58.

21 Art. 6:248 lid 2 BW: 'Een tussen partijen als gevolg van de overeenkomst geldende regel is niet van toepassing, voor zover dit in de gegeven omstandigheden naar maatstaven van redelijkheid en billijkheid onaanvaardbaar zou zijn.'

22 Art. 2 lid 2 onder c Wkkgz.

23 Legemaate, p. 704.

24 Governancecode Zorg, Principes voor goed bestuur en toezicht in Nederland, hoofdstuk 2, in het bijzonder 2.2 (open aanspreekcultuur) en 2.3 (leren), Waarden en normen, Utrecht 2017; ook eerdere codes kenden dergelijke richtlijnen.

25 Kamerstukken II 2015/16, 33149, nr. 46, brief van de minister van 29 juni 2016 aan de Tweede Kamer.

26 Toezicht op Goed Bestuur IGZ/NZa, juli 2016. 
ger en transparant belangrijke waarden zijn die zich niet verhouden tot zwijgcontracten waarbij geheimhouding wordt opgelegd over incidenten in de zorg en het verbod daarover met derden te spreken of melding daarvan te doen bij de IGJ. In het toezichtkader staat met zoveel woorden: 'Besluitvorming [door het bestuur, PK] vindt altijd plaats met het oog op patiënten en cliënten, interne betrokkenen en het publieke belang. Bestuurders stellen zich toetsbaar op in hun handelen. Van vaststellingsovereenkomsten die daaraan afbreuk doen of hierop qua openheid en transparantie een belemmering beogen (de zogenoemde zwijgcontracten) kan dan ook geen sprake zijn.'27

Zwijgcontracten die (mede) bepalen dat geen juridische procedures worden geëntameerd zijn reeds in strijd met artikel 17 Grondwet, waarin is bepaald dat niemand kan worden afgehouden van de rechter die de wet hem toekent. Als echter een partij juridische bijstand heeft, voldoende tijd heeft gehad hierover na te denken en weloverwogen deze beslissing neemt, ligt dit genuanceerder. ${ }^{28}$

Handhaving door de IGJ, dus langs bestuursrechtelijke weg, ten aanzien van het verzwijgen van ernstige incidenten is in zoverre mogelijk dat het bestuur op grond van de Wkkgz verplicht is calamiteiten (casus Tergooi) te melden bij de IGJ, hetgeen ook geldt voor geweld in de zorgrelatie (casus Cordaan) en bij ontslag van zorgverleners wegens ernstig disfunctioneren. Voorts heeft het bestuur zich te houden aan de wet (Wkkgz) en de regels van goed bestuur zoals uitgewerkt in de Code en in het toezichtkader van de IGJ en NZa. De IGJ en de minister beschikken voor toezicht en handhaving over het instrumentarium op grond van de Wkkgz (art. 24, 27 en 28 Wkkgz). De IGJ heeft naar aanleiding van haar eerdergenoemde onderzoek in 2017 aangegeven in geval van zwijgcontracten niet te zullen aarzelen tot het opleggen van een bestuursrechtelijke maatregel. ${ }^{29}$

Privaatrechtelijk is het contractueel afhouden van een wettelijk verplichte melding bij de IGJ nu al nietig op grond van het bepaalde in artikel 3:40 lid 2 BW. Voorts heeft de patiënt, afhankelijk van de omstandigheden, goede papieren om te bepleiten dat een zwijgcontract in strijd is met de goede zeden, volgens artikel 3:40 lid $1 \mathrm{BW}$ en artikel 7:902 BW, zeker als hierdoor zijn gang naar de rechter wordt belemmerd.

\section{Het wetsvoorstel}

Het wetsvoorstel beoogt, ondanks het reeds beschikbare juridisch instrumentarium, zwijgbedingen over incidenten in contracten nietig te verklaren. Het wil verduidelijken dat afspraken om over incidenten in de zorg te zwijgen ontoelaatbaar zijn en wil ervoor zorgen dat, door een dergelijk beding expliciet bij wet nietig te verklaren, geen van de partijen een beroep hierop kan doen. Het wetsvoorstel verstaat onder een zwijgbeding 'elk beding in een door contractspartijen gesloten overeenkomst dat het recht beperkt of ontneemt om informatie over een incident openbaar te maken of aan een derde te verstrekken' ${ }^{30}$ en is daarmee ruim geformuleerd. Bij het begrip 'incident' wordt aansluiting gezocht bij de defi-

27 Toezicht op Goed Bestuur, IGZ/NZa, Gedrag en cultuur, p. 8.

28 'Een tragische gebeurtenis in Tergooi', p. 34 en Legemaate, p. 704.

29 Nieuwsbericht IGJ: www.igj.nl/onderwerpen/zwijgcontracten/nieuws/2017/05/18/resultaten-onderzoekvaststellingsovereenkomsten-in-de-zorg.

30 Nieuw (voorgesteld) art. 11a lid 2 Wkkgz. 
nitie in het Uitvoeringsbesluit Wkkgz, maar dit wordt nu in de wet zelf opgenomen in artikel 1 Wkkgz. ${ }^{31}$ Hetzelfde geldt voor de Jeugdwet en de Wmo. Het gaat hierbij niet zozeer om de (vaststellings)overeenkomsten zelf waarin afspraken worden gemaakt over geheimhouding met betrekking tot schadevergoeding, maar om afspraken 'die ertoe leiden dat de patiënt niet mag spreken over het aan een schikking ten grondslag liggende incident met familieleden, vrienden of lotgenoten, dat partijen zich moeten onthouden van contacten met de media over het aan een schikking ten grondslag liggende incident, dat geen informatie mag worden verstrekt (...) aan de IGJ, dan wel dat de patiënt of cliënt dient af te zien van het indienen van een tuchtklacht en/of het doen van aangifte'32 (cursivering PK). Het wetsvoorstel laat nadrukkelijk contractuele afspraken over geheimhouding toe over andere zaken, bijvoorbeeld de hoogte van de financiële tegemoetkoming. Als een zwijgbeding onder de definitie valt en nietig is, laat dit onverlet dat de overige bepalingen van de overeenkomst in stand blijven (zie ook art. 3:41 BW).

Zoals hierboven aangegeven bestaat geen definitie van een zwijgcontract of zwijgbeding binnen een contract. De externe onderzoekscommissie Tergooi hanteert in haar rapport een engere definitie waarbij expliciet(er) het 'quid pro quo'-beginsel wezenlijk bestanddeel is van de overeenstemming: het moet volgens de commissie gaan om 'een overeenkomst waarin het ziekenhuis alleen aan bepaalde (financiële) wensen van de patiënt of de familie tegemoet wil komen als deze bereid zijn akkoord te gaan met door het ziekenhuis geformuleerde beperkende voorwaarden ${ }^{, 33} 34$ (cursivering PK). Overigens zal in de praktijk nauwelijks of geen verschil tussen beide definities bestaan. Immers ook in de definitie van het wetsvoorstel zal overeenstemming over de integrale tekst van de overeenkomst voor de zorgaanbieder voorwaarde zijn voor het betalen van schadevergoeding aan patiënt of nabestaanden waardoor het 'voor wat hoort wat'-beginsel ook hier geldt.

Het gaat er met dit wetsvoorstel vooral om krachtig te verduidelijken dat dergelijke bedingen maatschappelijk ongewenst zijn en in strijd met vigerende wet- en regelgeving in de zorg. Door wettelijk te verankeren dat een zwijgbeding in de zorg van rechtswege - dus op voorhand - nietig is, zal een rechterlijke toetsing aan artikel 3:40 lid $1 \mathrm{BW}$ (strijd met goede zeden) achterwege kunnen blijven. Anders gezegd zal door een toekomstig wettelijk verbod op zwijgcontracten in de zorg, voor zover dit überhaupt nog nodig zou moeten zijn, artikel 3:40 lid 2 BW kunnen worden ingeroepen waarin is bepaald dat 'strijd met een

31 Een incident is een niet-beoogde of onverwachte gebeurtenis die betrekking heeft op de kwaliteit en heeft geleid of had of zou kunnen leiden tot schade bij een cliënt. Calamiteiten of geweld in de zorgrelatie zijn ernstige vormen van incidenten en moeten worden gemeld bij de IGJ. Bij de Jeugdwet en de Wmo wordt eenzelfde definitie gehanteerd. Gebeurtenissen die tot schade hadden kunnen leiden, maar dat niet hebben gedaan of zullen doen, zijn incidenten en vallen dus onder het verbod van zwijgcontracten. Zie ook MvT Consultatieversie, p. 14.

32 Kamerstukken II 2018/19, 31839, nr. 633, p. 2.

33 'Een tragische gebeurtenis in Tergooi', p. 52-53.

34 Beperkende voorwaarden zoals: geen contact opnemen met de IGJ, geen tuchtklacht indienen tegen hulpverleners van het ziekenhuis, geen aangifte doen of gedane aangifte intrekken en geen contacten met de media over de gebeurtenis of de inhoud van de overeenkomst. 
dwingende wetsbepaling leidt tot nietigheid van de rechtshandeling' dan wel wanneer de bepaling strekt ter bescherming van een der partijen, tot vernietigbaarheid. ${ }^{35}$

Op zich zijn volgens de inspectie en de minister de bestaande handhavingsinstrumenten voor de inspectie om bestuursrechtelijk, bijvoorbeeld door het geven van een aanwijzing, te kunnen optreden tegen zwijgcontracten op grond van de Wkkgz nu al toereikend. ${ }^{36}$ Toch acht de regering een dergelijk verbod gewenst en voert als belangrijkste argumenten aan dat (i) de kwaliteit van de zorg door dergelijke afspraken in het geding komt, niet van fouten kan worden geleerd en dergelijke bedingen haaks staan op een open cultuur, (ii) essentiële waarden in de zorg als goed bestuur en openheid en transparantie over kwaliteit worden geschonden waardoor het vertrouwen in de zorg wordt ondermijnd en (iii) de positie van de patiënt door dergelijke afspraken onder druk kan komen te staan doordat hij in een kwetsbare positie verkeert en emotioneel belast wordt omdat hij de ernstige gebeurtenis niet met anderen kan bespreken. ${ }^{37}$ Nadrukkelijk geldt het wettelijk verbod op zwijgcontracten ook voor organisatorische verbanden binnen een instelling, zoals een Medisch Specialisten Bedrijf binnen een ziekenhuis. ${ }^{38}$ Het verbod van het aangaan van zwijgcontracten zal geen terugwerkende kracht kennen. ${ }^{39}$

\section{De internetconsultatie}

Van 11 maart tot 1 juni 2020 (verlengd vanwege corona) kon op internet gereageerd worden op het wetsvoorstel over zwijgcontracten in de zorg. Hiervan is negentien keer gebruik gemaakt, met reacties van particulieren en (belangen)organisaties, rijp en groen door elkaar. Een aantal belangenorganisaties onderschrijft het beginsel dat zwijgcontracten onwenselijk zijn, maar ziet geen toegevoegde waarde van een wettelijke regeling. In deze reacties wordt gesteld dat de wet nu al genoeg juridische handvatten biedt om op te treden tegen een zwijgcontract en wijst men erop dat door het veld al zelfregulering ${ }^{40}$ heeft plaatsgevonden die zich duidelijk uitspreekt voor openheid en transparantie en tegen zwijgbedingen. Deze organisaties zien serieuze risico's bij een wettelijke regeling: omdat (ook) de afspraak om niet met de media te spreken nietig is, kan dit leiden tot schending van de privacy van zorgverleners, reputatieschade of claims van derden, waardoor terug-

35 Bijzonder is dat art. 7:902 BW bepaalt dat vaststellingsovereenkomsten, vanwege het maatschappelijk verkeer, ook geldig zijn indien zij in strijd zijn met dwingend recht (denk aan art. 3:40 lid 2 BW), tenzij dit in strijd is met de goede zeden (denk aan art. 3:40 lid 1 BW). Zie B.J. Broekema-Engelen, TEC BW Boek 7, p. 3623 e.v.. Dit brengt mee dat zelfs nadat zwijgcontracten in de zorg wettelijk verboden zullen zijn verklaard, dit een vaststellingsovereenkomst met een zwijgbeding niet a priori nietig maakt, tenzij in strijd met de goede zeden. Strijdigheid met de goede zeden kon, ook vóór totstandkoming van dit wetsvoorstel, al veelal worden aangenomen. Echter, door een zwijgcontract in de zorg zó expliciet bij wet te verbieden, mag (ook) strijd met de goede zeden worden aangenomen. Een opmerkelijke cirkelredenering is het wel.

36 Kamerstukken II 2017/18, 31016, nr. 108, p. 37.

37 MvT Consultatieversie, p. 3 en 4.

38 Art. 1 lid 6 Wkkgz en MvT Consultatieversie, p. 13.

39 Art. 11a lid 3 onder b (gewijzigde) Wkkgz. Voor de Jeugdwet en Wmo geldt hetzelfde. Zie ook MvT Consultatieversie, p. 11 onder punt 9.

40 Genoemd worden bijvoorbeeld de Governancecode, de GOMA (Gedragscode Openheid na medische incidenten; betere afwikkeling Medische Aansprakelijkheid), KNMG-handreiking Omgaan met incidenten en klachten, enzovoort. 
houdendheid ontstaat om een minnelijke regeling te treffen en een rem wordt gezet op de gewenste openheid. Ook bestaat de vrees dat de wet het signaal afgeeft dat het delen van informatie met (sociale) media altijd is toegestaan, terwijl de zorgaanbieder zich in de media niet kan verweren vanwege zijn beroepsgeheim. ${ }^{41}$ Benadrukt wordt dat publieksvoorlichting hierin belangrijk is. Andere organisaties verwelkomen het wetsvoorstel, maar vinden dat bepaalde onderdelen verduidelijking of aanpassing behoeven. ${ }^{42}$

\section{Afsluiting}

De opvatting dat zwijgcontracten in de zorg, waarbij partijen afspreken om ernstige (bijna-)incidenten stil te houden, verwerpelijk zijn, wordt breed gedeeld. Naast het feit dat het moreel laakbaar is om patiënten of nabestaanden niet toe te staan hun leed te delen en hen af te houden van een gang naar toezichthoudende of rechtsprekende instanties, is het onder de bestaande wet- en regelgeving ook juridisch al aanvechtbaar. Zowel in het privaatrechtelijke als in het bestuursrechtelijke verkeer kan hiertegen worden opgetreden. Het slagen van een vordering in een juridische (civiele) procedure is niet op voorhand gegarandeerd en hangt af van de inhoud van het beding en de omstandigheden van het geval. Bij bestuursrechtelijk optreden door de inspectie ligt dit makkelijker. Het is het veld door de maatschappelijke commotie rondom ernstige gebeurtenissen, Kamervragen daarover en een brede uitvraag door de IGJ naar het vóórkomen van zwijgcontracten, glashelder (geworden) dat zwijgcontracten zich niet verhouden tot het beginsel van goed bestuur. Geen bestuurder van een zorginstelling zal zijn vingers branden en naleving van een zwijgbeding gaan eisen. Ook heeft de inspectie aangekondigd hiertegen te zullen optreden. Toch heeft de minister het nodig geoordeeld om met wetgeving te komen die dergelijke zwijgbepalingen nietig verklaart. Uit de internetconsultatie komt naar voren dat divers wordt gedacht over de noodzaak van een wettelijk verbod op zwijgcontracten en dat meerdere belangenorganisaties vrezen voor de bijeffecten hiervan. De nu al bestaande juridische mogelijkheden een zwijgbeding aan te vechten en de awareness van het veld in combinatie met de alerte houding hierin van de IGJ, maken dat deze wetgeving vooral moet worden gezien als een politiek statement of symboolwetgeving. Dat maakt dat het wetsvoorstel over zwijgcontracten in de zorg niet werkelijk noodzakelijk is. Kan het kwaad? Nee, maar dat is geen criterium voor het tot stand brengen van nieuwe wetgeving.

41 In deze sfeer de reacties van KNMG/NVZ/NFU, Jeugdzorg Nederland, GGZ Nederland/VGN, verzekeraar VvAA. Verzekeraar MediRisk wijst er op dat een regeling door mediation of arbitrage zal worden bemoeilijkt doordat de afgesproken geheimhouding tijdens mediation wordt doorkruist door de nietigheid van een zwijgbeding, zie ook MvT Consultatieversie, p. 7 en 8.

42 Patiëntenfederatie Nederland, Fonds Slachtofferhulp, Huis voor Klokkenluiders. Deze laatste organisatie bepleit o.a. om het verbod ook terugwerkende kracht te geven. 